\title{
Sexual Socialization Messages on Entertainment Television: Comparing Content Trends 1997-2002
}

\author{
Dale Kunkel \\ University of Arizona \\ Kirstie M. Farrar \\ University of Connecticut \\ Keren Eyal \\ University of Arizona \\ Erica Biely \\ University of California, Santa Barbara \\ Edward Donnerstein \\ University of Arizona \\ Victoria Rideout \\ Henry J. Kaiser Family Foundation
}

\begin{abstract}
Previous content analyses of sex on television have relied on differing measures and sampling strategies, which makes it difficult to compare patterns of sexual portrayals over time. This large-scale study ( $N=2,817$ programs) examines the sexual messages presented on television across both broadcast and cable channels over a 5-year period, applying identical measures to three biennial samples of program content. Results demonstrate that sexual talk and behavior are highly frequent aspects of the television environment. Talk about sex is shown more often than sexual behavior, though both types of content increased significantly from 1997/1998 to 2001/2002. Over that time span, the percentage of shows portraying sexual intercourse doubled from 7 to $14 \%$. Results also show that topics related to sexual risks or responsibilities (e.g., condom use, abstinence) are increasingly included on television, but nonetheless remain infrequent overall. Such safe sex messages occur most frequently in program environments where they are most relevant (i.e., when sexual intercourse is included in the story). The content analysis findings are discussed in terms of their implications for audience effects.
\end{abstract}

Address correspondence to: Dale Kunkel, Department of Communication, University of Arizona, Tucson, AZ 85721. E-mail: kunkel@u.arizona.edu 
One of the critical challenges facing young people today is developing a healthy understanding about sex. Such knowledge will form the foundation for their attitudes toward sex and their subsequent sexual behaviors throughout life. Television serves as a major contributing factor to such sexual socialization (American Academy of Pediatrics, 2001; Chapin, 2000; Donnerstein \& Smith, 2001) as it continues to dominate young people's media diet (Roberts \& Foehr, 2004). Thus, it is important to examine televised portrayals of sexuality even in an era when media alternatives, such as the Internet, dot the horizon.

The purpose of this study is to analyze the pattern of sexual messages found on television across recent years, in order to draw implications for audience effects. Media effects on social behaviors are not typically powerful and immediate, but rather the result of slow and gradual cumulative exposure to large numbers of similar types of messages over time. Accordingly, content analysis offers a useful methodology to identify consistent patterns of media messages to which viewers are likely to be exposed across the many thousands of television programs they typically view each year. Linking content analytic observations to existing theory and research about sexual socialization outcomes affords an excellent opportunity to estimate the nature of television's contribution to this critical area of social behavior, as well as to track any significant changes that occur over time. That is the goal of the research reported here.

In recent years, the public health concerns related to adolescent sexual behaviors have become increasingly prominent. For example, many teenagers have multiple sexual partners (Page, Hammermeister, \& Scanlan, 2000; Siegel, Klein, \& Roghmann, 1999) and report having sex without condoms at least some of the time (Parsons, Halkitis, Bimbi, \& Borkowski, 2000). Such risky sexual behavior can lead to a number of negative health outcomes, including unwanted pregnancies (Centers for Disease Control \& Prevention, 2000), STD infections (Alan Guttmacher Institute, 1999; American Social Health Association/Kaiser Family Foundation, 1998), and transmission of AIDS (Goldfarb, 1997). Young people, aged 15 to 24, account for approximately half of all new HIV infections (UNAIDS, 2004).

Many teens report that they do not get adequate information about sex from parents or at school during adolescence (Brown, Greenberg, \& Buerkel-Rothfuss, 1993). While a recent survey (Kaiser Family Foundation, 2003) found that 68\% of teens reported getting "some" or "a lot" of information about sex from their parents or from school, this still suggests that nearly one in three teenagers must turn to other sources for their information. Not surprisingly, media portrayals often fill this gap as the most readily available alternative. More than half $(51 \%)$ of adolescents cite television as an important source of information about birth control, contraception, and pregnancy prevention (Sutton, Brown, Wilson, \& Klein, 2002), and four out of ten (40\%) say they have gotten ideas for how to talk to their boyfriend or girlfriend about sexual issues from these sources (Kaiser Family Foundation, 1996, 1998). Adolescents also report using media examples to learn sexual and romantic scripts as well as norms for sexual behavior (Brown, Childers, \& Waszak, 1990). 
Many television programs in recent years-Buffy the Vampire Slayer, Dawson's Creek, Felicity, The OC, Clueless, Moesha-have included portrayals of teenagers and young adults involved in sexual relationships. How do these and other portrayals of sexual conduct affect young audiences? Direct empirical evidence of the impact of media sex is beginning to accumulate, and is consistent with theories of influence that predict significant effects (Huston, Wartella, \& Donnerstein, 1998). Such effects can be broken down into three broad categories: learning about sex and sexuality; shaping attitudes toward sexual activity; and influencing sexual behavior decisions.

First, young people can learn from the sexual topics presented on television. They can gain information pertaining to sexual health topics, such as condom failure rates or availability of the "morning after" pill, by viewing entertainment television (Collins, Elliott, Berry, Kanouse, \& Hunter, 2003; Kaiser Family Foundation, 1997). They can also learn the meaning of terms related to sex and sexuality that they see used on television (Greenberg, Linsangan, \& Soderman, 1993).

Second, young people's attitudes and beliefs regarding sex and sexual topics can be influenced by television. Watching sex on television influences young people's beliefs about the sexual behavior norms of people in the world around them (Buerkel-Rothfuss \& Mayes, 1981; Buerkel-Rothfuss \& Strouse, 1993). Similarly, attitudes about premarital sex (Greeson \& Williams, 1986), sexual stereotypes (Ward, 2002), sexual expectations (Aubrey, Harrison, Kramer, \& Yellin, 2003) and perceptions about the acceptability of extra-marital sex (Bryant \& Rockwell, 1994) have also been shown to change as a result of television viewing.

Third, direct empirical evidence increasingly suggests that watching sexual content on television contributes to an earlier initiation of sexual intercourse by adolescents. One correlational study (Brown \& Newcomer, 1991) found a positive association between viewing sex on TV and adolescent sexual behavior. While another correlational study (Peterson, Moore, \& Furstenberg, 1991) did not achieve the same result, recent longitudinal research that affords causal conclusions (Collins et al., 2004) revealed significant effects of viewing sexual content on television. Adolescents with heavy exposure to televised sex at Time 1 had earlier initiation of sexual behavior at Time 2, 1 year later. The effect is potent; youths who viewed sexual content one standard deviation above average behaved sexually like peers who were 9 to 17 months older, but who watched average amounts of sex on television.

While the evidence is increasing that exposure to sex on television contributes to sexual socialization and may accelerate underage sexual activity, there is also growing indication that televised portrayals addressing sexual risk or responsibility topics can help to sensitize adolescent and young adult viewers to critical public health concerns such as avoiding AIDS, other sexually transmitted diseases, and unwanted pregnancies. For example, Farrar (2006) has found that adolescent attitudes toward condom use and safe sex concerns can be improved by exposure to televised dramas in the lab that incorporate safe sex themes in their plots. In the field, CDC researchers report that viewers of a situation comedy in which a key character contracts AIDS 
became more concerned with safe sex issues and were more likely to seek AIDS testing to evaluate their health status (Kennedy et al., 2005). Similarly, Collins et al. (2003) found significant increases in knowledge about condom efficacy in 17\% of adolescent viewers who saw an episode of Friends in which a condom failed and caused an unplanned pregnancy for a featured character.

These findings underscore the importance of identifying the different types of sexual portrayals presented on television using content measures that are linked as much as possible to audience effects concerns. A portrayal of casual sex between two characters who have just met that includes no negative consequences holds profoundly different implications for audience effects than a portrayal in which such behavior leads to an STD transmission from one sexual partner to another. To better understand the likely effects of differing portrayals of sexual content on young audiences, it is important to consider the relevant theoretical perspectives that help to inform media effects analysis.

\section{Theoretical Perspectives on Media Sex Effects}

While such media theories as cultivation and priming may help to account for some of the influences identified above, social learning theory (Bandura, 1977) and its derivative social cognitive theory (Bandura, 1994) have been most widely applied by researchers in this topic area (Wiederman \& Whitley, 2002). These perspectives focus on specific behavioral influences (Gunter, 2002), with social cognitive theory accounting more extensively for cognitive processes that mediate the learning of social behaviors. Social learning theory affords an important function to televised role models, who offer examples of characters who weigh sexual options and/or engage in sexual behaviors, providing opportunities for young viewers to observe the outcomes of such situations. The theory also places importance on the salience of portrayals for a viewer, which is likely to be quite high for adolescents. This age group is typically grappling with an understanding of what are normative and appropriate sexual patterns and practices. Because viewers tend to pay more attention to portrayals that are relevant to them and their interests, adolescent audiences are particularly likely to learn from such depictions.

Furthermore, social learning theory emphasizes the importance of contextual variables in influencing media exposure outcomes (Bandura, 1994). For example, rewards to observed behaviors are likely to encourage the learning of these behaviors, whereas punishments or negative reinforcements are likely to discourage such learning. Identification with media characters is another key to the learning process such that greater similarity between viewer and character is likely to lead to a deeper relationship and increased learning from the character (e.g., Leyens \& Picus, 1973; Wilson, Kunkel, Linz, Donnerstein, Smith, Blumenthal, \& Gray, 1997). Thus, factors such as the outcomes of sexual behavior, the age and gender of the characters involved, and their relationships with sexual partners are important 
to consider when studying media portrayals of sexual behavior. All of these aspects of sexual portrayals are measured in the content analysis study reported here.

Another important theoretical perspective in this realm is Huesmann's "script theory" (1986). While it has been applied much more frequently to explain the effects of media violence than sexual content, it is equally relevant in either context. This theory argues that "scripts" for behavior are learned throughout development, and largely guide people's social behavior. These scripts are learned through observation, including portrayals presented in the media. According to Huesmann, there are several characteristics of media portrayals that make the modeling of scripts more likely. First, like social learning theory, attentional processes play an important role. In order to encode a script for behavior, one must first pay attention to it. Televised portrayals of scripts that are salient to the individual are therefore more likely to be encoded and stored for later retrieval in appropriate situations. Second, scripts that are perceived to be realistic are more likely to be encoded as meaningful. As mentioned previously, sexual situations are likely to be highly salient for young people and, not having as much experience with sexual situations in their own lives, they may perceive the sexual scripts presented on television as realistic. These two factors increase the likelihood that young people will pay attention to and encode the sexual scripts presented on television.

In sum, adolescents themselves state that they learn from televised sexual content. A growing body of empirical evidence, coupled with the theories mentioned here, supports the notion that television does indeed impact adolescent sexual socialization. Therefore, it is the goal of this study to identify the common patterns or approaches that are employed in the portrayal of sexual messages on television, framing these observations with an eye toward the implications for audience effects. Based on social learning theory and script theory, this study examines the critical contextual aspects of such televised messages, including the nature of the characters involved and the positive or negative outcomes associated with any sexual activity portrayed, among other key content variables analyzed.

\section{Previous Content Analysis Research}

Identifying patterns in the portrayals of sex on television has been a goal of researchers for many years. For example, research has consistently shown that sex is common during prime-time or "family hour" television viewing slots (Kunkel, Cope, \& Colvin, 1996; Lowry \& Shidler, 1993; Ward, 1995) as well as during soap operas (Greenberg \& Buselle, 1994; Greenberg et al., 1993). Previous research has also consistently shown that the most frequently portrayed sexual behaviors on television include kissing, embracing, and flirting (Franzblau, Sprafkin, \& Rubinstein, 1977; Kunkel et al., 1996) and that messages related to safe and healthy sexuality are highly infrequent (Greenberg et al., 1993; Lowry \& Shidler, 1993; Kunkel et al., 1996). Yet while numerous studies have examined the topic, 
the accumulation of knowledge across these various efforts has been somewhat constrained because of two key factors.

First, most studies in the past have limited their analysis to just a fragment of the overall television landscape. For example, studies have examined soap operas (Greenberg \& Buselle, 1994; Heintz-Knowles, 1996; Lowry \& Towles, 1989), talk shows (Greenberg \& Smith, 1995; Greenberg, Sherry, Buselle, Hnilo, \& Smith, 1997), teens' favorite programs (Cope \& Kunkel, 2002; Greenberg et al., 1993; Ward, 1995), and "Family Hour" programming (Kunkel, Cope, \& Colvin, 1996), with the broadest analysis encompassing all prime-time broadcast network shows (Franzblau, Sprafkin, \& Rubinstein, 1977; Lowry \& Shidler, 1993; Sapolsky \& Tabarlet, 1991; Silverman, Sprafkin, \& Rubinstein, 1979). This leaves many aspects of the television environment, such as cable channels (which now attract nearly half of all prime-time audiences), largely unexamined. Although these studies have delivered important pockets of knowledge, they fail to provide a clear and comprehensive picture of the patterns of sexual content across the overall television landscape.

A second factor limiting the utility of previous research is the lack of consistency across studies in defining and measuring sexual content in television programming. Idiosyncrasies across the research strategies employed render comparisons from one project to another difficult, as some examine sexual behavior but not talk, while others do just the opposite. Certainly, some patterns at a very basic level have been established, including the consistent finding that sexual portrayals are common throughout television, and an indication in the studies which have examined it that the potential negative consequences of sexual intercourse are rarely addressed (Huston et al., 1998). Still, more precise comparisons over time are problematic because of the lack of any common definitions and measures across disparate "one-off" studies.

The research presented here encompasses three biennial studies designed to overcome these two limitations. In this research, we apply the same measures to three large, broad-based samples of television content gathered in 1997-1998, 1999-2000, and 2001-2002. No previous program of research on sexual content has attempted to track such changes by applying consistent measures to comparable program samples gathered across multiple points in time. Thus, this study offers a valuable step forward in the accumulation of knowledge about the changing nature and extent of sexual messages conveyed on American television.

The sample was designed to encompass the full diversity of channel types across the overall television landscape. Ten networks were selected for sampling, including six from the broadcast sector and four from cable, roughly reflecting the slight dominance that broadcasters retain over cable channels in competing for audiences. The sample includes four affiliates of the large national broadcast networks (ABC, CBS, NBC, Fox), one independent broadcast station affiliated with a newer small network (WB), a public broadcast station (PBS), three basic cable networks (Lifetime, TNT, USA), and one premium cable channel (HBO). The spe- 
cific channels chosen for the study were the most heavily viewed according to Nielsen cumulative audience estimates within each of these industry categories when the study began in 1997.

A composite week design was employed to sample programs for each channel included in the study during each of the three television seasons examined. That sampling design yielded a collective total of approximately 1000 programs in each of the three television seasons studied, or roughly 3000 programs overall. Scientific content analysis techniques were then applied to all programs sampled.

The study addresses the following research questions:

RQ1: What is the frequency of sexual messages presented on television?

RQ2: What are the key contextual features associated with sexual intercourse presented on television?

RQ3: To what extent are sexual risk or responsibility concerns included in the sexual messages presented on television?

For each of these research questions, we examine change over time across the three television seasons studied, encompassing the 4-year period from 1997/1998 to $2001 / 2002$.

\section{METHOD}

\section{Sample of Programs}

This study employed the composite week sampling design that was first developed for the National Television Violence Study (Wilson et al., 1997). In this design, a composite week sample is created for each channel included in the study by randomly selecting programs that air in each time slot between 7:00 a.m. and 11:00 p.m. on each day of the week on each channel. Thus, at the end of each year in which the study is conducted, the sample includes a complete week's worth of programming (approximately 100 hours) for each channel that is representative of the content delivered throughout the television season. The process is replicated for each of the channels included in the study.

This tactic helps to avoid sampling issues associated with program cancellations and competitive shuffling of prime-time offerings, and reflects our understanding that audience effects are most likely to result from exposure to consistent patterns of messages across large numbers of programs rather than from exposure to individual shows that exert powerful effects. Sampling programs independently across the broad range of the television season using the composite week design maximizes confidence for generalizing the results to the overall universe of television programming, with the following caveat. The focus of this study is to assess the pattern of portrayals involving sex that are included in scripted entertainment 
programming; thus, newscasts (limited to daily news reports), live sports, and children's shows were excluded from the analysis. The sampling strategy resulted in 942 programs gathered during 1997/1998, 938 during 1999/2000, and 937 during 2001/2002, or a total of 2817 overall. The sampling was conducted in the Southern California area using Los Angeles-based stations, though by far most of the programming analyzed was nationally distributed by the targeted networks.

\section{Content Measures}

Audience effects theory and research make clear that both talk about sex as well as overt sexual behaviors contribute significantly to sexual socialization (Donnerstein \& Smith, 2001), and more specifically to teenagers' initiation of sexual activity (Collins et al., 2004). Accordingly, this study defines sexual content as including any depiction of sexual activity or sexually suggestive behavior; or talk about sexual topics, interests, intentions, or behaviors. Portrayals involving talk about sex are measured separately from those that include physical actions or behaviors. Coding for most variables was performed at the scene level, with a complementary measure in the area of sexual risks and responsibilities (described below) at the program level.

Codable sexual behaviors included physical flirting (behavior meant to arouse or promote sexual interest), passionate kissing (kissing that conveys a sense of sexual intimacy), intimate touching (touching of another's body in a way that is meant to be sexually arousing), sexual intercourse strongly implied (when a program portrays one or more scenes immediately adjacent in time and place to an act of sexual intercourse that is clearly inferred by narrative device), and sexual intercourse depicted (when a direct view is shown of any person engaged in the act of intercourse, regardless of the degree of nudity or explicitness).

The type of talk about sex was classified into one of six distinct categories: comments about own/others' sexual actions/interests; talk about sexual intercourse that has already occurred; talk toward sex (efforts to promote sexual activity that are conveyed directly to the desired sexual partner); talk about sex-related crimes; expert advice (the seeking and delivering of sincere advice about sex from an authority figure); and other.

For any material involving either sexual dialogue or behavior, the degree of scene focus on sex is judged, differentiating minor or inconsequential references and depictions from portrayals in which there is a substantial or primary emphasis on sex. Only sexual behaviors that are judged to be a "substantial" part of the scene in question are coded. In addition, all scenes that include sexual behavior are coded for degree of explicitness, which indicates the physical appearance of the characters involved in the behavior. The categories included provocative/suggestive dress or appearance (attire alone reflects a strong effort to flaunt one's sexuality); characters begin disrobing (the removing of clothing that reveals parts of the body not 
normally exposed); discreet nudity (characters are known to be nude but no private parts of the body are shown on-screen); and nudity (display of normally private parts, such as the buttocks or a woman's breasts). Greater explicitness should be likely to increase viewer attention to the content, as well as to enhance the likelihood of effects if it is sufficiently provocative to trigger an excitation-transfer effect (Zillmann, 1991).

When a scene includes sexual content, coders also judge whether it includes any mention or depiction of sexual risks or responsibilities. This term is used to describe the issues surrounding the serious outcomes that can be associated with human sexual activity. Three distinct risk or responsibility categories are examined: (1) sexual patience, including abstinence from sex or waiting for sex as a positive moral stance or a sound approach to avoiding sexual risks; (2) sexual precaution, including the use or discussion of preventative measures to reduce the risks involved in sexual activity; and (3) depiction of risks and/or negative consequences of sexual behavior.

For content fitting within any of these categories, the scene focus on sexual risks or responsibilities was judged to distinguish minor or inconsequential portrayals from those that were more central to the scene in question and therefore likely to be more meaningful to the audience. Finally, to complement the scene level variables, an assessment was conducted at the overall program level indicating whether or not each show that contains any sexual content places strong emphasis throughout on a risks or responsibilities program theme in one of three categories indicated above.

\section{Variable Scaling Information}

In the analyses we employ to generate findings for the study, some of the individual variables described above have been combined to create an index that will help to simplify the presentation of data. Here, we provide information to explicate how we have calculated several basic measures that we present in our subsequent report of findings.

To assess the level of sexual behavior, we report values on a scale of 1 to 4: a value of 1 indicates physical flirting, a value of 2 indicates intimate touching or passionate kissing, a value of 3 reflects sexual intercourse strongly implied, and a value of 4 represents intercourse depicted. Explicitness is measured on a scale of 0 to 4 , with 0 indicating none, 1 indicating suggestive/provocative dress, 2 indicating disrobing, 3 reflecting discreet nudity, and 4 indicating nudity. Both of these scales are reported as a threshold score within each scene. For example, a scene that contains kissing and intercourse strongly implied yields a score of 3, the higher of the two behavior values.

To assess the level of talk about sex, we are constrained by the fact that there is no apparent rationale for assigning greater or lesser values to any one of the various categories of sexual dialogue over another for purposes of considering their implications for audience effects. Therefore, we have chosen to construct a scale for the 
level of talk about sex that considers all scenes that present differing categories of dialogue as being of the same potential weight; and we have then based our calculation on the judgment that indicates the degree of focus, or emphasis, placed on any applicable talk category within the scene. The degree of focus involving talk about sex was measured on a four-point scale reflecting a continuum from minor to primary emphasis within each scene.

\section{Assessing the Reliability of the Data}

Judgments about the programming were recorded by 56 undergraduate student coders (27 for sample year 1997/1998; 14 for 1999/2000; and 15 for 2001/2002) who received approximately 80 hours of training each over a ten-week period. Reliability was assessed at two distinct levels: (1) agreement on unitizing decisions (i.e., identifying sexual content within scenes); and (2) agreement on the applicable measures used to describe the nature and context of the sexual content identified. This framework for reliability assessment is the same as that devised for the National Television Violence Study (Wilson et al., 1997), which represents the largest scientific study of television content yet conducted. The merits of this approach to reliability assessment have been explicated by Potter \& Levine-Donnerstein (1999). For unitizing decisions, the CIAM (Close Interval Around the Mode) is the key statistic. The mean agreement for identifying scenes that contained sexual content across all programs was $79 \%$ for the first sample of programs, $86 \%$ for the second and $91 \%$ for the third sample on the CIAM measure. Thus, the consistency for unitizing (i.e., identifying both sexual behavior and sexual dialogue within scenes) is highly credible given the complexity of the task and the number of coders involved. The consistency for coding scene-level contextual variables was also strong. For the first sample year, coders achieved agreement at $85 \%$ or above on 20 of the 23 measures reported and no variable was below $73 \%$ agreement. In the second sample year, coders achieved agreement at $88 \%$ or above on 21 of the 23 measures reported, with no variable below $80 \%$ agreement. In the third sample year, coders achieved agreement at $90 \%$ or above on 21 of the 23 measures reported, with no variable below $70 \%$ agreement. Inter-coder reliability on the program-level variables was $89 \%$ or above for all waves of the study. Overall, the reliability analyses establish strong confidence in the accuracy of the data reported.

\section{RESULTS}

In presenting our analyses, we start with examination of the most recent program sample gathered in 2001/2002, and then compare those findings with the observations from the previous two samples in 1997/1998 and 1999/2000. In analyzing 
change over time, we focus primarily upon comparing the 2001/2002 season to the 1997/1998 season. Data from 1999-2000 are presented to illuminate the consistency of the trends observed, while data from 1997/1998 and 2001/2002 are compared statistically to identify significant changes using chi-square analyses or $t$-tests as appropriate. By omitting statistical analyses of the mid-point in the 3 -year data set, we substantially reduce the overall number of comparisons and thus diminish the likelihood of encountering spurious significant results.

\section{Frequency of Sexual Content}

In the 2001/2002 television season, nearly two of every three shows (64\%) contained some sexual content (see Table 1). Few of these programs presented just a single, isolated scene involving sexual material; more than four of every five shows containing sexual messages $(82 \%)$ included two or more scenes with sexual themes or topics. Across all programs with any sexual content, there was an average of 4.4 scenes per hour involving sex. Thus, the data indicate that not only are sexual talk and behavior a common element in television programming, but that most shows including sexual messages devote substantial attention to the topic.

The lower portion of Table 1 differentiates the two primary types of sexual content examined in the study: talk about sex and sexual behavior. Across all programs examined, $61 \%$ included some talk about sex, whereas $32 \%$ presented some type of sexually-related physical behavior. In addition, programs containing talk about sex averaged 3.8 scenes per hour with such material; in comparison, programs that included overt sexual behaviors averaged 2.1 scenes per hour with physical actions by characters.

A final point of comparison between these two distinct types of sexual messages involves the average level of talk and behavior that is portrayed within scenes. Across all of the 2,453 scenes involving talk about sex, the exchanges averaged 2.8 on the four-point scale assessing degree of emphasis on sexual topics in the scene. This indicates that most scenes involving talk did not consist of isolated or minor references to sexual matters, but rather were at least moderate in terms of their focus on sexual themes and topics.

Across all of the 870 scenes involving sexual behavior in 2001/2002, the portrayals averaged 2.1 on the four-point scale assessing the highest level of behavior in the scene. This means that the average level of sexual behavior depicted fell in the moderate range, which involves such actions as passionate kissing and intimate touching.

To gain a clearer picture of the cases involving intercourse presented on television, which arguably hold the greatest potential for socializing effects on young viewers, we have isolated those shows that present scenes with sexual intercourse depicted or strongly implied from the remaining shows that portray other sexual behaviors but which do not present any scenes in which intercourse occurs. This 
TABLE 1

Summary of Sexual Content

\begin{tabular}{|c|c|c|c|}
\hline & 1998 & 2000 & 2002 \\
\hline $\begin{array}{l}\text { Percentage of programs with any sexual content } \\
\text { Of programs with any sexual content: }\end{array}$ & $56 \% \mathrm{a}$ & $68 \%$ & $64 \%_{\mathrm{b}^{* *}}$ \\
\hline $\begin{array}{l}\text { Average number of scenes per hour } \\
\text { containing sex }\end{array}$ & $3.2 \mathrm{a}$ & 4.1 & $4.4_{\mathrm{b} * *}$ \\
\hline Number of shows & 528 & 642 & 595 \\
\hline Number of hours & 594.5 & 685 & 679 \\
\hline Number of scenes & 1930 & 2830 & 2992 \\
\hline $\begin{array}{l}\text { Percentage of Programs with Any Talk About Sex } \\
\text { Of programs with any talk about sex: }\end{array}$ & $54 \% \mathrm{a}$ & $65 \%$ & $61 \%_{\mathrm{b} * *}$ \\
\hline $\begin{array}{l}\text { Average number of scenes per hour } \\
\text { containing talk }\end{array}$ & $3.0_{\mathrm{a}}$ & 3.8 & $3.8_{\mathrm{b} * *}$ \\
\hline Average level of talk in scenes & 2.8 & 2.8 & 2.8 \\
\hline Number of shows & 504 & 614 & 571 \\
\hline Number of hours & 564.5 & 648.5 & 642.5 \\
\hline Number of scenes with talk about sex & 1719 & 2470 & 2453 \\
\hline $\begin{array}{l}\text { Percentage of programs with any sexual behavior } \\
\text { Of programs with any sexual behavior: }\end{array}$ & $23 \% \mathrm{a}$ & $27 \%$ & $32 \%_{\mathrm{b} * *}$ \\
\hline $\begin{array}{l}\text { Average number of scenes per hour } \\
\text { containing behavior }\end{array}$ & $1.4_{\mathrm{a}}$ & 1.8 & $2.1_{\mathrm{b}^{* *}}$ \\
\hline Average level of behavior in scenes & 2.0 & 2.1 & 2.1 \\
\hline Number of shows & 221 & 256 & 299 \\
\hline Number of hours & 294.5 & 345 & 411 \\
\hline Number of scenes with sexual behavior & 420 & 608 & 870 \\
\hline Total number of shows & 942 & 938 & 937 \\
\hline
\end{tabular}

Note. Any given scene may contain talk about sex as well as sexual behavior. Due to the occurrence of such overlap within scenes, the data for talk about sex cannot be summed with the data for sexual behavior to yield the findings for any sexual content overall.

Findings with different subscripts that have one asterisk attached [e.g., a/b*] are significantly different at $p<.05$. Findings with different subscripts that have two asterisks attached [e.g., a/b**] are significantly different at $p<.01$.

latter group, which contains portrayals of such actions as physical flirting, passionate kissing, and intimate touching, is labeled "Programs with Precursory Behaviors Only" (see Table 2).

Programs that present precursory behaviors only are slightly more common (18\% of programs overall) than programs which present sexual intercourse depicted or strongly implied (14\% of programs overall). Nonetheless, the latter finding presented here represents one of the most striking observations from this study. Across the entire 2001/2002 sample of nearly 1000 randomly selected programs, roughly one in every seven (14\%) includes a portrayal of sexual intercourse. 
TABLE 2

Summary of Sexual Behavior

\begin{tabular}{|c|c|c|c|}
\hline & 1998 & 2000 & 2002 \\
\hline $\begin{array}{l}\text { Percentage of programs with any sexual behavior } \\
\text { Of programs with any sexual behavior: }\end{array}$ & $23 \% \mathrm{a}$ & $27 \%$ & $32 \%_{\mathrm{b} * *}$ \\
\hline $\begin{array}{l}\text { Average number of scenes per hour containing } \\
\text { behavior }\end{array}$ & $1.4_{\mathrm{a}}$ & 1.8 & $2.1_{\mathrm{b} * *}$ \\
\hline Average level of behavior in scenes & 2.0 & 2.1 & 2.1 \\
\hline Average level of explicitness in program & 0.9 & 1.1 & 1.1 \\
\hline Number of shows & 221 & 256 & 299 \\
\hline Number of hours & 294.5 & 345 & 411 \\
\hline Number of scenes & 420 & 608 & 870 \\
\hline $\begin{array}{l}\text { Percentage of programs with precursory behaviors only } \\
\text { Of programs with precursory behaviors only: }\end{array}$ & $16 \%$ & $17 \%$ & $18 \%$ \\
\hline $\begin{array}{l}\text { Average number of scenes per hour containing } \\
\text { precursory }\end{array}$ & $1.4_{\mathrm{a}}$ & 1.5 & $1.9_{\mathrm{b} * *}$ \\
\hline Average level of behavior in scenes & 1.7 & 1.8 & 1.8 \\
\hline Average level of explicitness in program & 0.4 & 0.5 & 0.4 \\
\hline Number of shows & 151 & 164 & 164 \\
\hline Number of hours & 176.5 & 191.5 & 192.5 \\
\hline Number of scenes with precursory behavior & 244 & 286 & 357 \\
\hline $\begin{array}{l}\text { Percentage of programs with any intercourse behavior } \\
\text { Of programs with any intercourse behavior: }\end{array}$ & $7 \% \mathrm{a}$ & $10 \%$ & $14 \%_{\mathrm{b}^{* *}}$ \\
\hline $\begin{array}{l}\text { Average number of scenes per hour containing } \\
\text { intercourse }\end{array}$ & $0.7 \mathrm{a}$ & 1.0 & $0.9{ }^{*}$ \\
\hline Average level of behavior in scenes & 2.5 & 2.5 & 2.4 \\
\hline Average level of explicitness in program & 2.0 & 2.2 & 2.0 \\
\hline Number of shows & 70 & 92 & 135 \\
\hline Number of hours & 118 & 153.5 & 218.5 \\
\hline Number of scenes with intercourse & 88 & 147 & 200 \\
\hline Number of all sexual behavior scenes & 176 & 322 & 513 \\
\hline Total number of shows & 942 & 938 & 937 \\
\hline
\end{tabular}

Note. Findings with different subscripts that have one asterisk attached [e.g., a/b*] are significantly different at $p<.05$. Findings with different subscripts that have two asterisks attached [e.g., a/ $\left.\mathrm{b}^{* *}\right]$ are significantly different at $p<.01$.

Another interesting point of comparison involves the degree of explicitness associated with the portrayal of sexual behaviors. Across all programs including any sexual behavior, the average level of explicitness was very low at 1.1 on the scale, indicating most sexual behaviors on television do not involve nudity. When intercourse is involved in the program, however, the average level of explicitness increases to 2.0 on the four-point scale, with discreet nudity a common element but no full nudity shown on any channel other than HBO.

Finally, our data show that scenes in which sexual intercourse is strongly implied rather than directly depicted, represent the most common approach for televi- 
sion to convey that love-making has occurred. Of the 200 cases of intercourse observed in the 2001/2002 sample, $82 \%$ were strongly implied compared to $18 \%$ directly depicted (i.e., characters were shown during the act of intercourse, though typically with only limited or obstructed views of the bodies).

\section{Change over time since the 1997/1998 television season}

Despite a slight decline from levels observed in 1999/2000, the overall proportion of programs with sexual content in 2001/2002 is significantly greater than the level observed in 1997/1998, indicating that the overall amount of sexual messages on television remains up significantly across the 4-year time span studied. This increase can be seen in our data in Table 1 comparing both the proportion of programs that include sexual content (56\% in $1997 / 1998$ vs. $64 \%$ in $2001 / 2002, \chi^{2}(1)$ $=10.84, p<.01)$ as well as the average number of scenes involving sex $(3.2$ per hour in $1997 / 1998$ vs. 4.4 per hour in 2001/2002) in those programs that contain sexual material $[t(1282)=6.30, p<.01]$.

Talk about sex increased significantly from 1997/1998 to 2001/2002 both in terms of the percentage of programs with talk (54\% in 1997/1998 and 61\% in 2001/2002) $\left(\chi^{2}(1)=10.61, p<.01\right)$ as well as the average number of scenes per hour (3.0 in 1997/1998 compared to 3.8 in 2001/2002) that include talk about sex $[t(1206)=4.30, p<.01]$. The average level of talk about sex found within scenes held constant at 2.8 across all three sample years. Data from the 1999/2000 television season suggest that most of the significant changes we have identified in talk about sex first occurred between 1997/1998 and 1999/2000.

In contrast, a more steady and consistent increase in the presentation of sexual behaviors on television across the 4-year time span is palpable in our data. The proportion of programs with depictions of sexual behavior has increased significantly from $23 \%$ in $1997 / 1998$ to $32 \%$ in $2001 / 2002\left(\chi^{2}(1)=16.76, p<.01\right)$. Similarly, the average number of scenes of sexual behavior has increased consistently over time, from 1.4 per hour in $1997 / 1998$ to 2.1 per hour by $2001 / 2002[t(703)=6.86$, $p<.01]$.

Focusing more closely on portrayals of sexual intercourse, we again identify an upward trend in the frequency of these depictions (see Table 2). More specifically, the percentage of programs that present sexual intercourse doubles from 1997/ 1998 (7\%) to 2001/2002 (14\%), with this increase proving statistically significant $\left(\chi^{2}(1)=23.52, p<.01\right)$. Similarly, programs in $2001 / 2002$ include significantly more scenes per hour of intercourse than that found in 1997/1998 [t(335) $=2.49, p$ $<.05]$, but there was no difference in the average level of explicitness associated with such depictions $[t(203)=.10, p=.92]$.

In sum, across the 4 years of television programming sampled by this study, a wide range of sexual portrayals on television are on the rise. Both the prevalence of programs that include sexual messages as well as the number of scenes with sexual 
content included in those shows have increased significantly. Portrayals of sexual intercourse have also become more frequent, and are now found in roughly one of every seven programs examined by this research.

\section{Contextual Features of Scenes with Sexual Intercourse}

Televised portrayals of intercourse play a role in socializing young viewers to the patterns of behavior that are normative in our culture. Questions such as the age at which one should have intercourse, or the strength of the relationship that typically exists between intercourse partners, are important concerns for many young people. In this section we examine some of the contextual features associated with intercourse portrayals that, based upon existing media effects theory and research, should be expected to influence perceived norms for sexual behavior, one of the many important influences on adolescent sexual behavior.

Table 3 presents several important contextual factors likely to shape the meaning of these portrayals for the audience. First, the age of characters involved in intercourse was examined. Across all intercourse scenes identified by the study in $2001 / 2002$, we see that most characters involved (83\%) are adults aged 25 or older.

TABLE 3

Contextual Elements in Scenes with Sexual Intercourse

\begin{tabular}{|c|c|c|c|c|c|c|}
\hline & \multicolumn{2}{|c|}{1998} & \multicolumn{2}{|c|}{2000} & \multicolumn{2}{|c|}{2002} \\
\hline & $n$ & $\%$ & $n$ & $\%$ & $n$ & $\%$ \\
\hline \multicolumn{7}{|l|}{ Apparent age of the characters involved } \\
\hline Child $(<12)$ & 1 & $1 \%$ & 0 & $0 \%$ & 0 & $0 \%$ \\
\hline Teen (13-17) & 6 & $3 \%$ & 27 & $9 \%$ & 12 & $3 \%$ \\
\hline Young adult (18-24) & 40 & $23 \% \mathrm{a}$ & 68 & $23 \%$ & 54 & $14 \%_{\mathrm{b}^{* *}}$ \\
\hline Adult (25+) & 129 & $73 \% \mathrm{a}$ & 199 & $68 \%$ & 334 & $83 \%_{\mathrm{b} * *}$ \\
\hline Total number of characters & 176 & $100 \%$ & 294 & $100 \%$ & 400 & $100 \%$ \\
\hline \multicolumn{7}{|l|}{ Participants' relationship with one another } \\
\hline Have an established relationship & 47 & $53 \%$ & 74 & $50 \%$ & 123 & $61 \%$ \\
\hline $\begin{array}{l}\text { Have met before but no established } \\
\text { relationship }\end{array}$ & 25 & $28 \%$ & 37 & $25 \%$ & 37 & $19 \%$ \\
\hline Have just met & 9 & $10 \%$ & 23 & $16 \%$ & 15 & $7 \%$ \\
\hline Can't tell & 7 & $8 \%$ & 13 & $9 \%$ & 25 & $13 \%$ \\
\hline \multicolumn{7}{|l|}{ Drugs } \\
\hline Use of drugs in scene & 2 & $2 \%$ & 2 & $1 \%$ & 3 & $1 \%$ \\
\hline \multicolumn{7}{|l|}{ Alcohol } \\
\hline Use of alcohol in scene & 13 & $15 \%$ & 15 & $10 \%$ & 22 & $11 \%$ \\
\hline Total number of scenes & 88 & $100 \%$ & 147 & $100 \%$ & 200 & $100 \%$ \\
\hline
\end{tabular}

Note. Findings with different subscripts that have one asterisk attached [e.g., a/b*] are significantly different at $p<.05$. Findings with different subscripts that have two asterisks attached [e.g., a/ $\left.\mathrm{b}^{* *}\right]$ are significantly different at $p<.01$. 
Only a small proportion of those engaged in intercourse (14\%) are young adults (aged 18-24) and even fewer are teenagers (3\%).

The majority of all scenes with intercourse in 2001/2002 (61\%) involve characters who have an established relationship with one another, a category that includes but is not limited to marriage. Roughly one of every five scenes of intercourse $(19 \%)$ portray characters having sex who know one another but have not yet established an ongoing relationship, and another $7 \%$ of scenes present characters having sex when they have just met. Very few scenes of intercourse include any use of drugs (1\%), although alcohol use was somewhat more common, appearing in $11 \%$ of scenes.

\section{Change over time since the 1997/1998 television season}

The only notable shift observed across the 4-year time span of the study involves the age range of characters included in intercourse scenes. In 2001/2002, the characters in intercourse portrayals are significantly more likely to be older adult characters. Adults aged 25 years and above $\left(\chi^{2}(1)=8.07, p<.01\right)$, account for $83 \%$ of all characters shown engaging in intercourse in 2001/2002, as compared to $73 \%$ in $1997 / 1998$. In contrast, depictions of young adults aged 18-24 who engage in intercourse decreased significantly from $23 \%$ of all such behavior shown in 1997/ 1998 to $14 \%$ in 2001/2002. In other words, while portrayals of intercourse have become more common on television over time, it is less likely that the characters involved will be young adults, and more likely the characters will be age 25 or older. All of the other contextual features examined have remained relatively stable over time.

\section{Genre Differences}

With the exception of daily newscasts, sport competitions, and children's shows, all programs appearing on television were sampled in exact proportion to their frequency of broadcast on the channels studied. The findings from our data analyses reported above, which encompass all programs in the study, are therefore representative of the overall television environment, notwithstanding the limited caveat above. While it would of course be impossible for any individual viewer to watch all this content, the logic of the sampling design is that over time most viewers are likely to be exposed to a broad range of offerings from all of these channels, which are among the most popular on television. Thus, our data provide a rough index of what most viewers would expect to encounter in their television viewing over the long haul.

Nevertheless, preferences for varying program types can influence individual viewing patterns, and thus it is informative to examine differences in sexual content across distinct program genres. For viewers whose exposure is heavily skewed 
toward any particular genre, such evidence can be helpful in identifying differences in the overall pattern of sexual messages to which they are likely exposed. Table 4 presents frequency breakdowns for sexual content observed across seven common program genres for the 2001-2002 television seasons.

These data reveal both similarities and differences in patterns across genres. In terms of overall frequency of sexual content, it is noteworthy that all but one of the seven genres includes sexual material in a majority of its programs. Reality shows, defined here to encompass all nonfiction programming besides news magazines (e.g., 60 Minutes, Dateline, 20/20), include sexual content in only $28 \%$ of programs. In contrast, program types with the greatest likelihood of presenting sexual material include soap operas (96\%), movies (87\%), comedies (73\%), and dramas $(71 \%)$.

Situation comedies stand out for contributing the greatest number of scenes with sexual content, at an average of 7.8 per hour. Soap operas and movies both have a higher percentage of programs that contain some sexual content than do comedy series, but neither of these categories can match the number of scenes per hour with either talk about sex or sexual behavior that are contained in episodes of comedy series.

Comparative analyses over time for data across genres are too intricate to incorporate into the space available for this article, as we have done in most other sections. However, it is worth noting that our findings appear to be relatively stable within genres over the period 1997-2002 on nearly all of our measures.

\section{Safe Sex Messages}

In analyzing programs for this study, each scene involving any sexual content was evaluated for any mention or depiction of sexual risk or responsibility themes such as condom use. As mentioned in our introduction, there is increasing evidence that exposure to such messages contributes to beliefs, attitudes, and/or behaviors that are likely to reduce the risk of unwanted pregnancy or sexually transmitted diseases. Table 5 indicates that the treatment of such issues within individual scenes is quite limited overall. In 2001/2002, only $6 \%$ of all scenes with sexual content incorporate any message about the risks or responsibilities of sexual activity. Another way of framing this finding is to observe that only about one in every 17 times that the topic of sex arises on television is there any mention of a sexual risk or responsibility concern, regardless of the degree of emphasis involved on such safe sex messages.

Sexual precaution was the most frequent topic, though it appeared in only 90 scenes across the composite week, representing a total of $3 \%$ of all scenes with sexual content. Nearly half of the scenes involving precaution topics $(n=40)$ either mentioned or depicted the use of a condom. The depiction of risks and/or negative consequences was found in $2 \%$ of all scenes with sexual content. Examples in this 


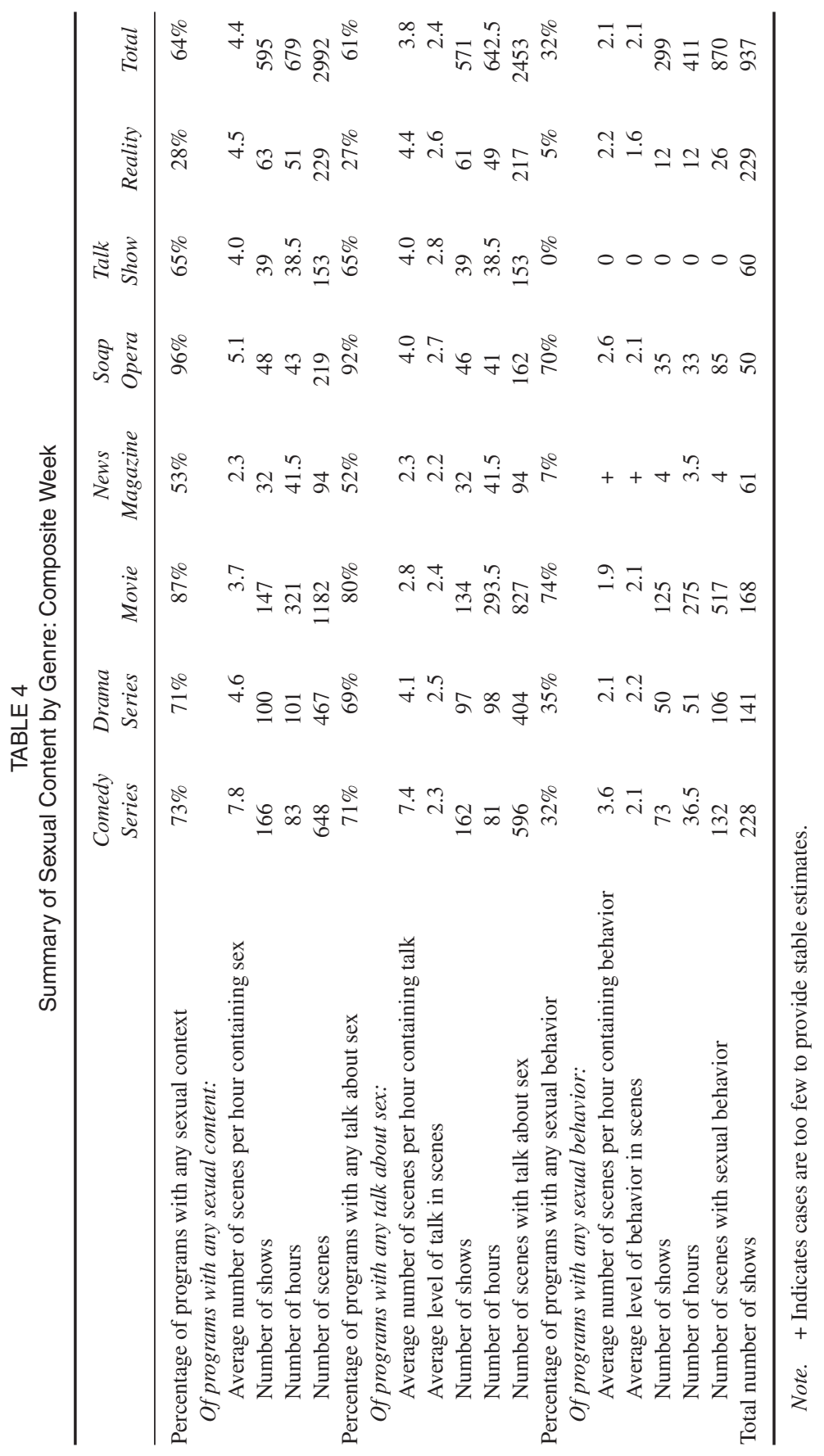


TABLE 5

Distribution of Risk/Responsibility Topics Included in Scenes

\begin{tabular}{|c|c|c|c|c|c|c|}
\hline \multirow[b]{2}{*}{ Types of risk/responsibility } & \multicolumn{2}{|c|}{1998} & \multicolumn{2}{|c|}{2000} & \multicolumn{2}{|c|}{2002} \\
\hline & $n$ & $\%$ & $n$ & $\%$ & $n$ & $\%$ \\
\hline Sexual precaution & 35 & $2 \%$ & 68 & $2 \%$ & 90 & $3 \%$ \\
\hline Depiction of risks/negative consequences & 45 & $2 \%$ & 50 & $2 \%$ & 75 & $2 \%$ \\
\hline Sexual patience & 13 & $1 \%$ & 23 & $1 \%$ & 25 & $1 \%$ \\
\hline Number of scenes with any $R / R$ & $78 \ddagger$ & $4 \% \mathrm{a}$ & 131 辣 & $5 \%$ & $170_{\text {蛘 }}$ & $6 \% \mathrm{~b}^{*}$ \\
\hline Total number of scenes with sexual content & 1930 & - & 2830 & - & 2992 & - \\
\hline
\end{tabular}

Note. $\$ 15$ cases contained two aspects of risk/responsibility within a single scene. Thus, a total of only 78 independent scenes were found to include any risk/responsibility. 10 cases contained two aspects of risk/responsibility within a single scene. Thus, a total of only 131 independent scenes were found to include any risk/responsibility. $\$ 20$ cases contained two aspects of risk/responsibility within a single scene. Thus, a total of only 170 independent scenes were found to include any risk/ responsibility.

Findings with different subscripts that have one asterisk attached [e.g., a/b*] are significantly different at $p<.05$. Findings with different subscripts that have two asterisks attached [e.g., a/b**] are significantly different at $p<.01$.

category presented such serious, life-altering outcomes as unwanted pregnancy and abortion, as well as characters who contract AIDS from unprotected sexual intercourse. Finally, portrayals that incorporate a theme of sexual patience were found in $1 \%$ of all scenes with sexual content throughout the composite week. Examples in this category emphasized the virtues of sexual abstinence, virginity, or simply waiting until one is certain s/he is ready to assume the responsibilities associated with a sexual relationship.

\section{Presence of risk or responsibility messages in different program contexts}

It also makes sense to analyze our findings from an overall program perspective, evaluating the frequency with which shows that include sexual material present a risk or responsibility message anywhere within the same program. In the 2001-2002 season, $15 \%$ of all programs with sexual content included at least one scene addressing risk or responsibility somewhere within the program (see Table 6).

Another important perspective for evaluating the frequency with which risk or responsibility topics receive treatment on television can be gained by focusing exclusively on the programs that present portrayals of more advanced sexual content. Programs that include either talk about sexual intercourse that has already oc- 
TABLE 6

Presence of Sexual Risk/Responsibility Topics

in Different Program Contexts

\begin{tabular}{lccc}
\hline & 1998 & 2000 & 2002 \\
\hline All programs with any sexual content & & & \\
$\quad$ Percentage of shows with any mention of R/R & $9 \% \%_{\mathrm{a}}$ & $10 \%$ & $15 \%_{\mathrm{b}}{ }^{* *}$ \\
$\quad$ Number of shows with any mention of R/R & 45 & 61 & 92 \\
$\quad$ Total number of shows & 528 & 642 & 595 \\
All programs with intercourse related content & $14 \%_{\mathrm{a}}$ & $17 \%$ & $26 \%_{\mathrm{b}} * *$ \\
$\quad$ Percentage of shows with any mention of R/R & 28 & 43 & 51 \\
Number of shows with any mention of R/R & 203 & 259 & 200 \\
Total number of shows & & & \\
\hline
\end{tabular}

Note. Findings with different subscripts that have one asterisk attached [e.g., a/b*] are significantly different at $p<.05$. Findings with different subscripts that have two asterisks attached [e.g., a/ $\left.\mathrm{b}^{* *}\right]$ are significantly different at $p<.01$.

Programs with intercourse-related content include shows with scenes in which there is talk about intercourse that has already occurred; or which intercourse behavior is depicted or strongly implied.

curred, or that present portrayals with characters engaging in sexual intercourse behavior, are arguably the contexts in which risk or responsibility messages are most relevant and, from an audience effects perspective, likely to be most critical. Programs that include any of these types of portrayals are labeled as "intercourse-related content" on Table 6, which reveals that these shows have a greater probability of including a risk or responsibility message than the $15 \%$ level observed across all programs with any sexual content. More specifically, $26 \%$ of programs that feature intercourse-related content include at least one risk or responsibility message somewhere within the show.

We also examined the degree of emphasis that is placed on sexual risk topics in those scenes that address such issues. Our data from 2001/2002 indicate that risk or responsibility concerns receive primary emphasis in only one out of every five scenes $(20 \%)$ in which these topics are addressed, while another $17 \%$ of the cases receive substantial emphasis within a scene. The remainders of all scenes (63\%) that mention risk or responsibility issues devote only inconsequential or minor emphasis to the topic.

\section{Overall program emphasis on risks or responsibilities}

Finally, the study also gathered original data at the level of each program judged as a whole. For this variable of program-level emphasis on risk or responsibility, coders evaluated whether such concerns were a central theme that ran throughout the program. This analysis, reported in Table 7, indicates that programs with a primary 
TABLE 7

Programs with Primary Emphasis on Sexual R/R Themes

\begin{tabular}{lccc}
\hline & 1998 & 2000 & 2002 \\
\hline All programs with any sexual content & & & \\
$\quad$ Percentage of shows with primary emphasis on R/R & $1 \%$ & $2 \%$ & $1 \%$ \\
$\quad$ Number of shows with primary emphasis on R/R & 7 & 16 & 8 \\
$\quad$ Total number of shows & 528 & 642 & 595 \\
All programs with intercourse related content & $2 \%$ & $4 \%$ & $2 \%$ \\
Percentage of shows with primary emphasis on R/R & 5 & 11 & 3 \\
Number of shows with primary emphasis on R/R & 203 & 259 & 200 \\
Total number of shows & & & \\
\hline
\end{tabular}

Note. Programs with intercourse-related content include shows with scenes in which there is talk about intercourse that has already occurred; or in which intercourse behavior is depicted or strongly implied.

emphasis on risk or responsibility themes were extremely rare overall in 2001/ 2002 , representing only $1 \%$ of all shows on television that contained sexual content. Considering just the programs that include intercourse-related content (i.e., talk about intercourse already occurred; intercourse behavior depicted or strongly implied), the percentage increases very slightly to $2 \%$. In raw numbers, this translates to 3 of the 200 programs with intercourse-related content that placed primary emphasis on a sexual risk or responsibility theme.

In sum, portrayals or discussions of safe sex messages are rare both at the scene and program level. Additionally, when these topics are addressed, they tend to be only an inconsequential or minor part of the scene or program in question. However, it is noteworthy that safe sex messages are more common in shows that feature intercourse-related content.

\section{Change over time since the 1997/1998 television season}

Our findings for the 2001/2002 television season make clear that messages conveying risk or responsibility concerns are relatively infrequent amidst the large number of scenes that include either sexual talk or behavior. The presence of risk or responsibility messages has inched upward over time since 1997-1998. For example, the percentage of scenes with sexual content that include any risk or responsibility message has increased from $4 \%$ in 1997/1998 to 6\% in 2001/2002 (see Table 5); while that change is statistically significant because of the large number of scenes included in the analysis $\left(\chi^{2}(1)=6.60, p<.05\right)$, it is only a modest shift in practical terms.

Analyzing the data from a program level perspective, Table 6 reveals a significant increase over time in the percentage of programs with sexual content that in- 
clude at least some risk or responsibility message. In 1997/1998, only $9 \%$ of shows with sexual material included any risk or responsibility content, as compared to $15 \%$ in $2001 / 2002\left(\chi^{2}(1)=12.58, p<.01\right)$. Similarly, the proportion of programs with intercourse-related content that included any mention or depiction of sexual risk or responsibility topics climbed from $14 \%$ in $1997 / 1998$ to $26 \%$ in $2001 / 2002$ $\left(\chi^{2}(1)=8.76, p<.01\right)$. Clearly, the overall trend is moving toward greater attention to these topics within programs where risk and responsibility issues are most relevant.

While treatment of risk or responsibility concerns is increasing as an element within television shows with sexual content, such topics rarely receive primary emphasis within a program, and that pattern has held steady over time. Programs that include a primary emphasis on sexual risk or responsibility themes account for just $1-2 \%$ of all shows with sexual content across all three of the program samples included in the study (see Table 7).

In sum, the over-time comparisons make clear that sexual risk or responsibility messages remain infrequent overall, but are appearing increasingly on the television screen, particularly in programming that includes more advanced sexual content. Viewers are significantly more likely to encounter such messages today than they were just a few years ago. It remains the case, however, that while sex on television is commonplace, attention to sexual risk and responsibility concerns is an uncommon occurrence.

\section{DISCUSSION}

At the outset of this article, it was established that increasing evidence indicates that sexual talk (Ward, 2002; Ward \& Rivadeneyra, 1999) and behavior (Collins et al., 2004; Eyal, 2004; Farrar, 2006) on television contribute to sexual socialization among youth and emerging adults. It is therefore important to consider the pattern of messages about sex presented on television, both to help media effects researchers better appreciate the ecology of the message environment as well as to inform broader social and policy debates surrounding the topic. Indeed, it is the overall pattern of messages that is of critical importance, as it is well understood that most media effects in this realm are slow and cumulative processes that result from extended exposure over time. Not only do the sexual patterns presented on television provide behavioral learning opportunities; as Gunter (2002) notes, exposure to talk about sex "can contribute to norms and expectations concerning how to be sexual, why and when sex is appropriate, and with whom" (p. 89).

This study provides elaborate analysis of sexual messages found in the 2001/ 2002 television season, along with a comparison of those findings to evidence gathered in recent years from complementary program samples. Our data show that sexual messages continue to be a highly frequent element across the television 
landscape. Setting aside news, sports, and children's shows, which were omitted from the study, our research found that nearly two of every three programs (64\%) in 2001/2002 include some sexual content. Among these shows, there are 4.4 scenes per hour with sexual content, including either talk about sex, sexual behavior, or both. Furthermore, our findings demonstrate that sexual messages on television have increased substantially over the 5-year period analyzed by this research. On average, recent viewers are significantly more likely to have encountered shows with sexual content, as compared to the situation in the late 1990s.

To help contextualize these data, consider a comparison with evidence regarding the frequency of violence on television. According to the final report of the National Television Violence Study (Smith et al., 1998), 61\% of programs included some violent portrayals, with violence occurring at a rate of 6.8 interactions per hour. (Scene data was not reported; interactions refer to a perpetrator acting against a target within a scene, which means that any scene in which a target "fights back" would yield two interactions.) Given the widely accepted axiom that violence is prevalent and widespread throughout television as a medium, and the relative similarity of our findings to the NTVS data, it seems reasonable to conclude that sexual messages are at least in the same league as violence in terms of overall presence. In light of the total amount of time most individuals devote to television annually, the overall volume of exposure to sexual content clearly holds significant implications for audience effects.

At a more detailed level, talk about sex is featured far more often on television than the portrayal of any sexually-related behaviors. In addition, the prevalence of talk about sex has increased significantly since our series of studies began in 1997/ 1998. Similar increases were observed over time in the portrayal of sexual behaviors on television, with nearly one out of every three shows including such content in the most recent sample. Given that Collins et al. (2004) have found that adolescents' exposure to talk about sex contributes just as significantly as their viewing of sexual behaviors to an acceleration of acts of intercourse, these findings clearly warrant equal attention to the concern devoted to behavioral depictions.

One of the most noteworthy findings identified by the study is a significant increase in the frequency with which sexual intercourse is portrayed on television. Across nearly 1000 shows examined for the 2001/2002 television season, roughly one of every seven programs (14\%) includes a portrayal of sexual intercourse either depicted or strongly implied. This is a significant increase from the $7 \%$ level that was observed 4 years earlier, in 1997/1998. Given the average levels of television viewing, it seems highly likely that most viewers will encounter such content on a regular basis.

When intercourse is portrayed on television, the most common approach is to imply the act rather than to depict it directly. For example, a scene might show a couple kissing and caressing one another, beginning to undress as they stumble into a darkened bedroom, with the scene dissolving before the actual act of inter- 
course ensues; or a couple might be shown awakening in bed together with the conversation centering on the lovemaking they had performed the night before. The fact that intercourse is strongly and clearly implied in a story rather than depicted directly does not diminish its likely socialization effects for young viewers. Indeed, children who are old enough to have developed physically and emotionally such that they are interested in sex will also be old enough to clearly draw the intended inference from scenes of intercourse strongly implied. This interpretation is corroborated by focus group research with children as young as age eight (Kaiser Family Foundation, 1996).

The extent to which programs address sexual risk or responsibility topics continues to move upward, albeit at a modest pace. The most basic of our multiple indicators in this area is the proportion of all scenes of sexual content that include any mention or depiction of risk or responsibility concerns. This statistic has increased from $4 \%$ in $1997 / 1998$ to $6 \%$ in $2001 / 2002$. However, few would likely argue that every single scene with sexual material ought to incorporate some message about social responsibility. A more ecologically valid perspective may be offered by our analysis of the proportion of programs with sexual content that address sexual risk or responsibility concerns somewhere within the story-telling. From this perspective, risk or responsibility themes were included in $9 \%$ of shows with sexual content in 1997/1998, increasing to $15 \%$ in 2001/2002. From either a scene or a program view, however, risk or responsibility messages on television remain sparse.

The rate at which sexual risk or responsibility topics are addressed is markedly higher in those programs that portray more advanced sexual situations, such as including talk about intercourse that has already occurred or depictions of intercourse behavior. In these shows Moreover, that rate has increased consistently during our study. The percentage of intercourse-related programs that address these issues nearly doubled from 1997/1998 (14\%) to 2001/2002 (26\%). Although the treatment of sexual risk or responsibility topics remains infrequent overall, it is becoming much more common in those programs which, by their plot-lines, make such issues most relevant.

Finally, it should be noted that while the frequency with which risk or responsibility topics are addressed is clearly on the rise, such issues rarely receive prominent attention. Only about a third of all scenes that address sexual risk or responsibility place substantial or primary emphasis on the topic. The large majority of such scenes involve only inconsequential or minor mentions about safe sex concerns. In addition, only $1 \%$ of all shows with sexual content place primary emphasis throughout the program on a sexual risk or responsibility theme. This lack of emphasis on sexual risk or responsibility topics reflects a missed opportunity for the medium of television to contribute positively to a critically important public health issue. Indeed, even the U.S. Surgeon General (2001) has called upon the industry to strive to address such concerns in their entertainment story-telling, reflecting the important role that television can play in influencing behavior. 
If entertainment television "teaches" young people lots about sex, it has offered relatively little so far in terms of safe sex messages that could help sensitize adolescent and young adult viewers to the health risks and potentially life-altering consequences of sexual activity. While the pattern of recent change is encouraging, the overall level of sexual risk or responsibility messages remains low, even in scenarios where sexual intercourse is included prominently in a program. When this ongoing series of studies was initiated in 1997, the number of sexual risk or responsibility messages on television was too low for any meaningful examination of variability in their content beyond the most basic distinction, such as parsing them by topic area (i.e., sexual patience, sexual precaution, depiction of risks and/or negative consequences). As sexual risk and responsibility messages increase in frequency, it will be important for researchers to examine them in greater depth. We hope to pursue such efforts in our future investigations, and believe it will be fruitful for others to explore the same terrain as television's treatment of sexual health concerns continues to evolve over time.

\section{ACKNOWLEDGMENT}

The research reported here was supported by grants awarded to the first author by the Henry J. Kaiser Family Foundation of Menlo Park, California, a nonprofit public health philanthropy.

\section{REFERENCES}

Aubrey, J. S., Harrison, K., Kramer, L., \& Yellin, J. (2003). Variety versus timing. Gender differences in college students' expectations as predicted by exposure to sexually oriented television. Communication Research, 30, 432-460.

Alan Guttmacher Institute. (1999). Facts in brief: Teen sex and pregnancy [Online]. Available: http:// www.agi-usa.org/sections/teen-preg.html

American Academy of Pediatrics. (2001). Sexuality, contraception, and the media. Pediatrics, 107, 191-194.

Bandura, A. (1977). Social learning theory. Englewood Cliffs, NJ: Prentice-Hall.

Bandura, A. (1994). Social cognitive theory of mass communication. In J. Bryant \& D. Zillmann (Eds.) Media effects: Advances in theory and research (pp. 61-90). Hillsdale, NJ: Erlbaum.

American Social Health Association/Kaiser Family Foundation (1998). STDs in America.

Brown, J. D., \& Newcomer, S. F. (1991). Television viewing and adolescents' sexual behavior. Journal of Homosexuality, 21, 77-91.

Brown, J. D., Childers, K. W., \& Waszak, C. S. (1990). Television and adolescent sexuality. Journal of Adolescent Health Care, 11, 62-70.

Brown, J. D., Greenberg, B. S., \& Buerkel-Rothfuss, N. L. (1993). Mass media, sex, and sexuality. Journal of Adolescent Health Care, 11, 62-70.

Bryant, J., \& Rockwell, S. C. (1994). Effects of massive exposure to sexually oriented prime-time television programming on adolescents' moral judgment. In D. Zillmann, J. Bryant, \& A.C. Huston 
(Eds.). Media, children, and the family: Social scientific, psychodynamic, and clinical perspectives (pp. 183-195). Hilldsale, NJ: Erlbaum.

Buerkel-Rothfuss, N. L., \& Mayes, S. (1981). Soap opera viewing: The cultivation effect. Journal of Communication, 32(3), 108-115.

Buerkel-Rothfuss, N. L., \& Strouse, J. S. (1993). Media exposure and perceptions of sexual behaviors: The cultivation hypothesis moves to the bedroom. In B. S. Greenberg, J. D. Brown \& N. L. Buerkel-Rothfuss (Eds.), Media, sex, and the adolescent (pp. 225-247). Cresskill, NJ: Hampton Press.

Centers for Disease Control and Prevention (2000). National and state-specific pregnancy rates among adolescents - United States, 1995-1997. Morbidity \& Mortality Weekly Report, 49(27).

Chapin, J. R. (2000). Adolescent sex and mass media: A developmental approach. Adolescence, 35, 799-811.

Collins, R. L., Elliott, M. N., Berry, S. H., Kanouse, D. E., \& Hunter, S. B. (2003). Entertainment television as a healthy sex educator: The impact of condom-efficacy information in an episode of Friends. Pediatrics, 112(5), 1115-1121.

Collins, R. L., Elliott, M. N., Berry, S. H., Kanouse, D. E., Kunkel, D., Hunter, S. B., \& Miu, A. (2004). Watching sex on television predicts adolescent initiation of sexual behavior. Pediatrics, 114(3), 280-289.

Cope, K. M., \& Kunkel, D. (2002). Sexual messages in teens' favorite prime-time TV programs. In J. D. Brown, J. Steele, \& K. Walsh-Childers (Eds.), Sexual teens, sexual media. Hillsdale, NJ: Erlbaum.

Donnerstein, E., \& Smith, S. (2001). Sex in the media: Theory, influences, and solutions. In D. G. Singer \& J. L. Singer (Eds.), Handbook of children and the media (pp. 289-307). Thousand Oaks, CA: Sage.

Eyal, K. (2004). The effects of television drama shows on emerging adults'sexual attitudes and perceptions. Unpublished Doctoral Dissertation, University of California, Santa Barbara.

Farrar, K. M. (2006). Sexual intercourse on television: Do safe sex messages matter? Journal of Broadcasting \& Electronic Media, 50, 635-650.

Franzblau, S., Sprafkin, J. N., \& Rubinstein, E. A. (1977). Sex on TV: A content analysis. Journal of Communication, 27(2), 164-170.

Goldfarb, A. F. (1997). Adolescent sexuality. Annals of the New York Academy of Sciences, 816, 395-403.

Greenberg, B. S., \& Buselle, R. W. (1994). Soap operas and sexual activity. Menlo Park, CA: Kaiser Family Foundation.

Greenberg, B. S., Linsangan, R., \& Soderman, A. (1993). Adolescents' reactions to television sex. In B. S. Greenberg, J. D. Brown, \& N. L. Buerkel-Rothfuss, (Eds.) Media, sex and the adolescent (pp. 196-224). Cresskill, NJ: Hampton Press.

Greenberg, B. S., \& Smith, S. (1995). The content of television talk shows: Topics, guests and interactions. Menlo Park, CA: Kaiser Family Foundation.

Greenberg, B. S., Sherry, J. L., Busselle, R. W., Hnilo, L. R., \& Smith, S. W. (1997). Daytime television talk shows: Guests, content, and interactions. Journal of Broadcasting \& Electronic Media, 41, 412-426.

Greenberg, B. S., Stanley, C., Siemicki, M., Heeter, C., Soderman, A., \& Linsangan, R. (1993). Sex content on soaps and the prime-time television series most viewed by adolescents. In B. S. Greenberg, J. D. Brown, \& N. L. Buerkel-Rothfuss, (Eds.). Media, sex, and the adolescent (pp. 29-44). Cresskill, NJ: Hampton Press.

Greeson, L. E., \& Williams, R. A. (1986). Social implications of music videos for youth: An analysis of the content and effects of MTV. Youth \& Society, 18, 177-189.

Gunter, B. (2002). Media sex: What are the issues? Mahwah, NJ: Erlbaum.

Heintz-Knowles, K. E. (1996). Sexual activity on daytime soap operas: A content analysis of five weeks of television programming. Menlo Park, CA: Kaiser Family Foundation. 
Huesmann, L.R. (1986). Psychological processes promoting the relation between exposure to media violence and aggressive behavior by the viewer. Journal of Social Issues, 42, 125-139.

Huston, A. C., Wartella, E., \& Donnerstein, E. (1998). Measuring the effects of sexual content in the media. Menlo Park, CA: Kaiser Family Foundation.

Kaiser Family Foundation (1996, June). The 1996 Kaiser Family Foundation survey on teens and sex: What they say teens today need to know and who they listen to. Menlo Park, CA: Author.

Kaiser Family Foundation (1997). Documenting the power of television: A survey of regular E.R viewers. Menlo Park, CA: Kaiser Family Foundation.

Kaiser Family Foundation (1998, Spring). Kaiser Family Foundation and YM Magazine national survey of teens: Teens talk about dating, intimacy, and their sexual experiences. Menlo Park, CA: Author.

Kaiser Family Foundation (2003). National survey of adolescents and young adults: Sexual health knowledge, attitudes and experiences. Menlo Park, CA: Kaiser Family Foundation.

Kennedy, M.G., O'Leary, A., Wright-Fofanah, S, Dean, E., Chen, Y., \& Baxter, R. (2005). Effects on HIV stigma of viewing an HIV-relevant storyline in a television situation comedy.

Kunkel, D., Cope, K. M., \& Colvin, C. (1996). Sexual messages on family hour television: Content and context. Menlo Park, CA: Kaiser Family Foundation.

Leyens, J.P., \& Picus, S. (1973). Identification with the winner of a fight and name mediation: Their differential effects upon subsequent aggressive behavior. British Journal of Social and Clinical Psychology, 12, 374-377.

Lowry, D. T., \& Shidler, J. A. (1993). Prime time TV portrayals of sex, "safe sex," and AIDS: A longitudinal analysis. Journalism Quarterly, 70, 628-637.

Lowry, D. T., \& Towles, D. E. (1989). Prime time TV portrayals of sex, contraception, and venereal diseases. Journalism Quarterly, 66, 347-352.

Page, R. M., Hammermeister, J. J., \& Scanlan, A. (2000). Everybody's not doing it: Misperceptions of college students' sexual activity. American Journal of Health Behavior, 24(5), 387-394.

Parsons, J. T., Halkitis, P. N., Bimbi, D., \& Borkowski, T. (2000). Perceptions of the benefits and costs associated with condom use and unprotected sex among late adolescent college students. Journal of Adolescence, 23, 377-391.

Peterson, J. L, Moore, K. A, \& Furstenberg, F. F. (1991). Television viewing and early initiation of sexual intercourse: Is there a link? Journal of Homosexuality, 21, 93-119.

Potter, W. J., \& Levine-Donnerstein, D. (1999). Rethinking validity and reliability in content analysis. Journal of Applied Communication Research, 27, 258-284.

Roberts, D., \& Foehr, U. (2004). Kids and media in America. Cambridge, United Kingdom: Cambridge University Press.

Sapolsky, B. S., \& Tabarlet, J. O. (1991). Sex in prime time television: 1979 vs. 1989. Journal of Broadcasting \& Electronic Media, 35, 505-516.

Siegel, D. M., Klein, D. I., \& Roghmann, K. J. (1999). Sexual behavior, contraception, and risk among college students. Journal of Adolescent Health, 25, 336-343.

Silverman, L. T., Sprafkin, J. N., \& Rubinstein, E. A. (1979). Physical contact and sexual behavior on prime-time TV. Journal of Communication, 29(1), 33-43.

Smith, S., Wilson, B., Kunkel, D., Linz, D., Potter, W.J., Colvin, C., \& Donnerstein, E. (1998). Violence in television programming overall: University of California Santa Barbara study. In National Television Violence Study, Volume 3 (pp. 5-220). Thousand Oaks, CA: Sage Publications.

Sutton, M. J., Brown, J. D., Wilson, K. M., \& Klein, J. D. (2002). Shaking the tree of knowledge: Where adolescents learn about sexuality and contraception. In J. D. Brown, J. R. Steele, \& K. Walsh-Childers (Eds.), Sexual teens, sexual media: Investigating media's influence on adolescent sexuality (pp. 25-55). Mahwah, NJ: Erlbaum.

UNAIDS (2004, July). 2004 Report on the global AIDS epidemic.

U.S. Surgeon General. (2001). Call to action to promote sexual health and responsible sexual behavior. Rockville, MD: U.S. Public Health Service. 
Ward, L. M. (1995). Talking about sex: Common themes about sexuality in the prime-time television programs children and adolescents view most. Journal of Youth \& Adolescence, 24, 595-615.

Ward, L. M. (2002). Does television exposure affect emerging adults' attitudes and assumptions about sexual relationships? Correlational and experimental confirmation. Journal of Youth \& Adolescence, $31(1), 1-15$.

Ward, L. M., \& Rivadeneyra, R. (1999). Contributions of entertainment television to adolescents'sexual attitudes and expectations: The role of viewing amount versus viewer conceptual issues. European Journal of Social Psychology, 23, 39-52.

Wiederman, M. W., \& Whitley, B. E. Jr. (2002). Handbook for conducting research on human sexuality. Mahwah, NJ: Erlbaum.

Wilson, B., Kunkel, D., Linz, D., Potter, W. J., Donnerstein, E., Smith, S., Blumenthal, E., \& Gray, T. (1997). Violence in television programming overall: University of California Santa Barbara study. In National Television Violence Study, Volume 1. Thousand Oaks, CA: Sage.

Zillmann, D. (1991). Television viewing and physiological arousal. In J. Bryant \& D. Zillmann (Eds.), Responding to the screen: Reception and reaction processes (pp. 135-167). Hillsdale, NJ: Lawrence Erlbaum Associates. 